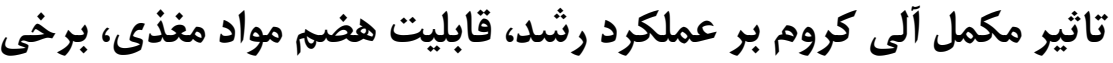

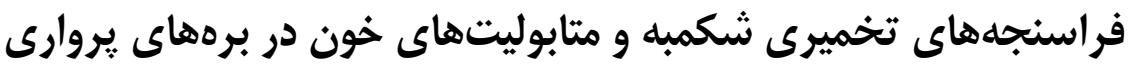

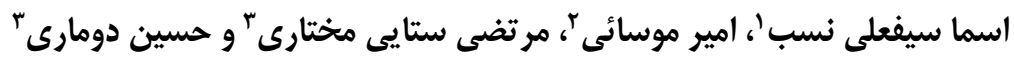

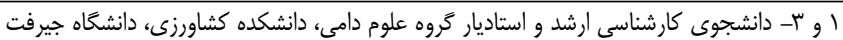

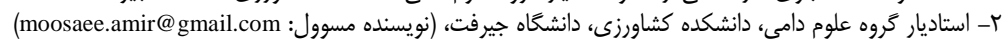

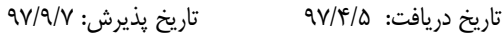

VE

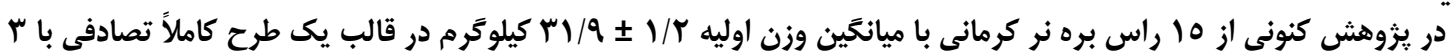

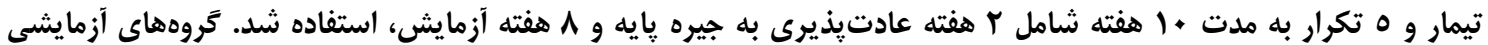

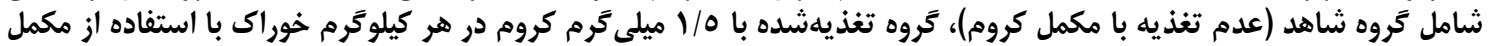

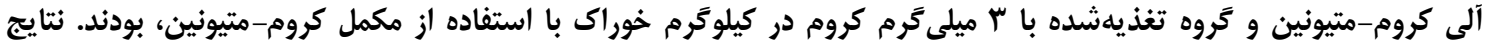

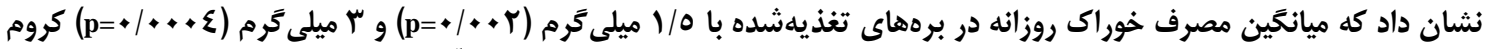

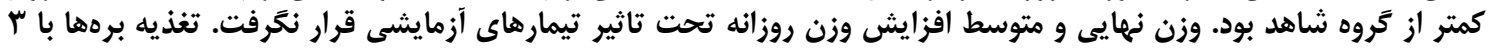

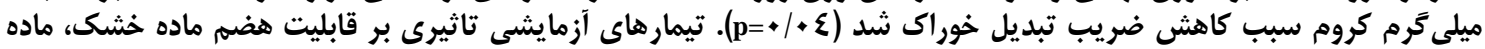

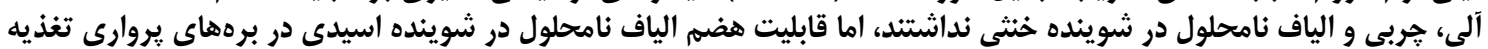

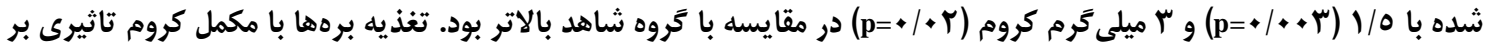

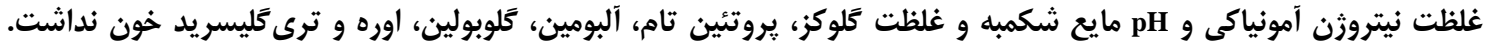

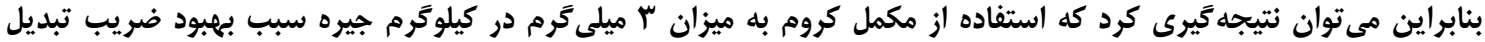
خوراك برههاى بروارى مى شودان

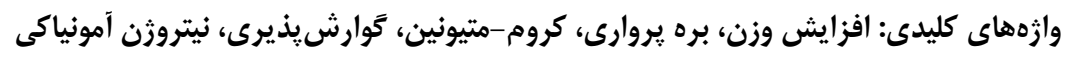

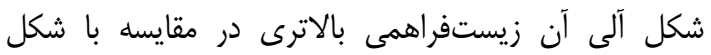

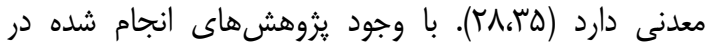

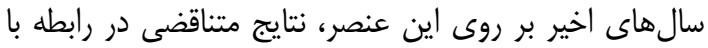

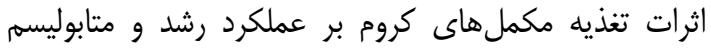

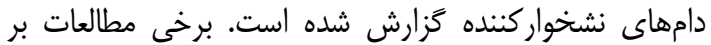

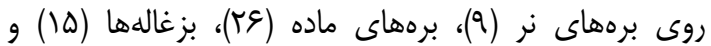

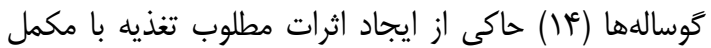

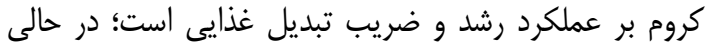

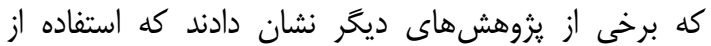

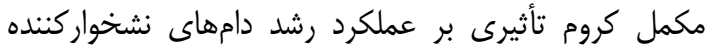

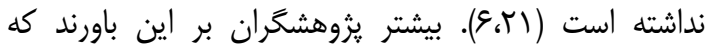

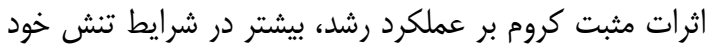

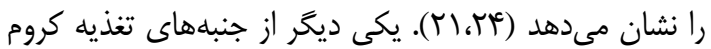

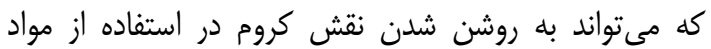

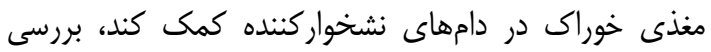

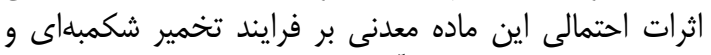

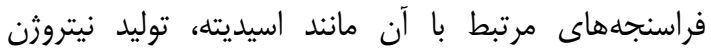

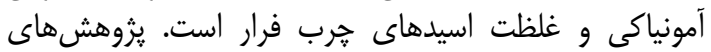

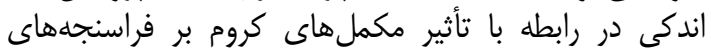

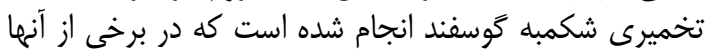

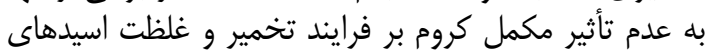

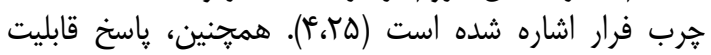

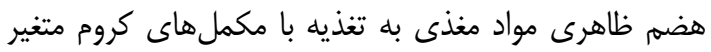

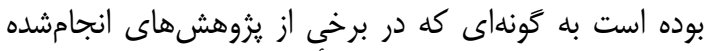

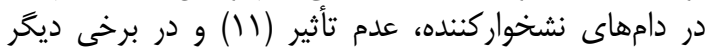
بهبود قابليت هضم مواد مغذى (V)

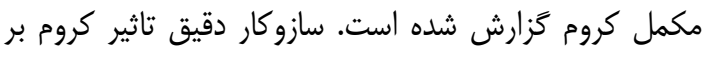

مقدمه - مقائ افزايش جمعيت كشور و متعاقب آن افزايش تقاضا براى

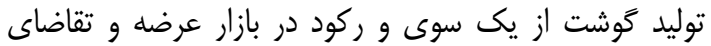

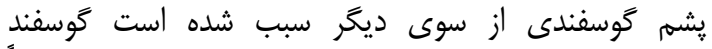

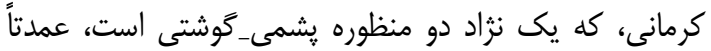

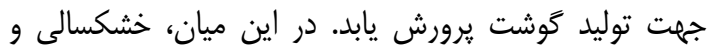

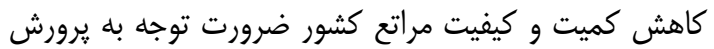

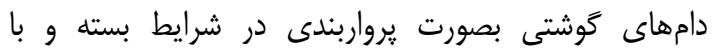

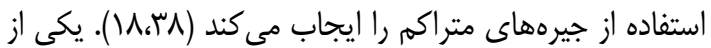

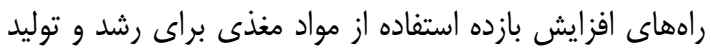

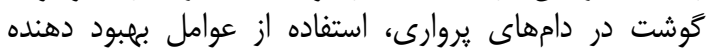

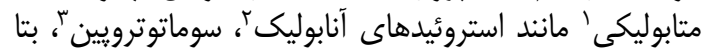

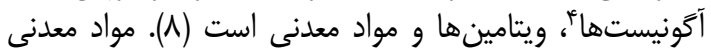

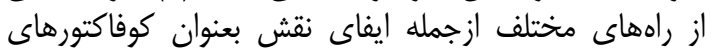

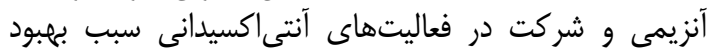

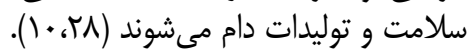

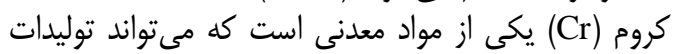

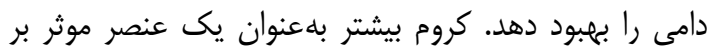

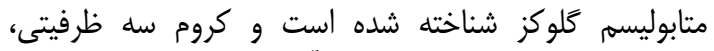

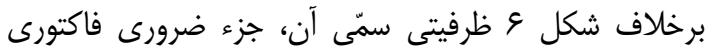

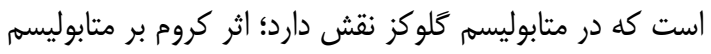

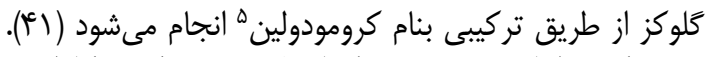

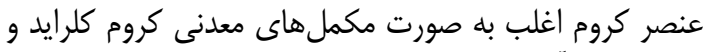

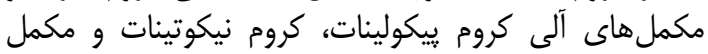

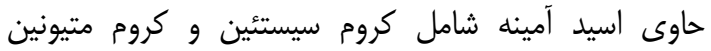

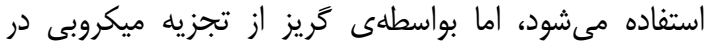
شكمبه و جذب از طريق ناقلهاى اختصاصى در روده كوريك، 
جمعآورى كل مدفوع (Tr،ר)، در هفته آخر آزمايش از طريق

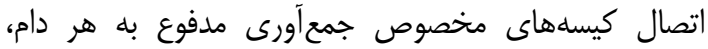

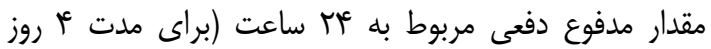

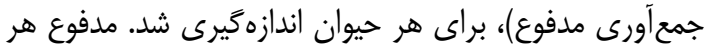

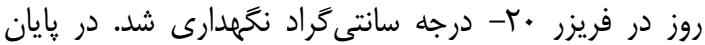

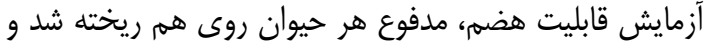

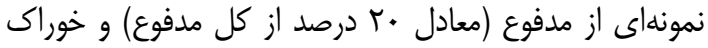

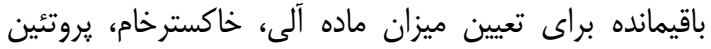

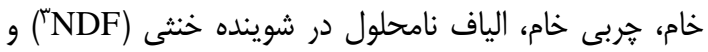

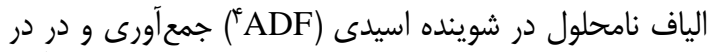

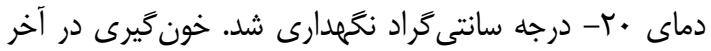

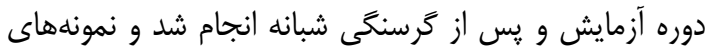

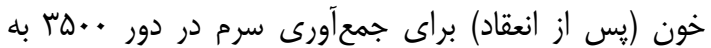

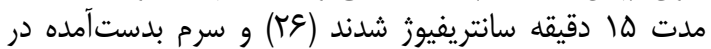

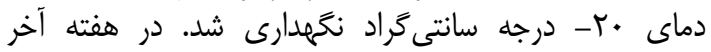

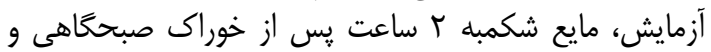

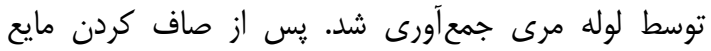
شكمبه با پارجه متقال، pH آن با استفاده از (pH/Temp, Milwaukee, Europe)

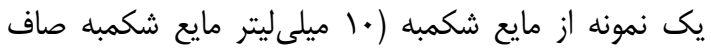

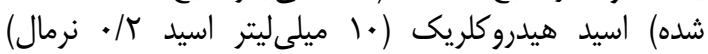

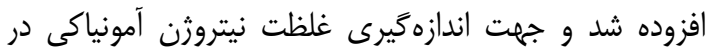

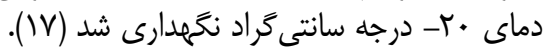

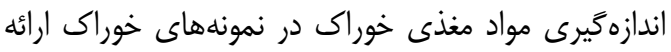

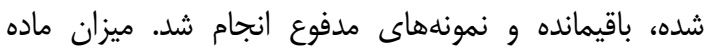

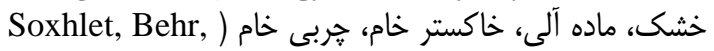

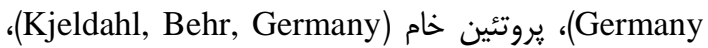
اندازهكيرى (Fiber Analysis, Velp, Italy) ADF, NDF

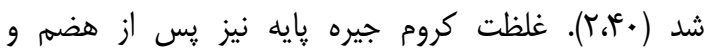

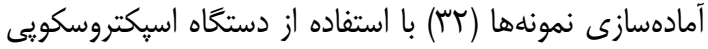

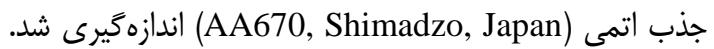

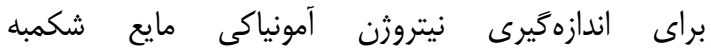

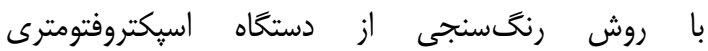
استفاده شد. در اين (Lambda-25 Perkin Elmer, USA) روش إز محلول معرف رنكى فنل (حاوى فنل و سديم

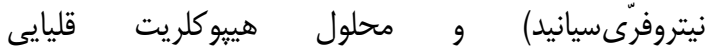

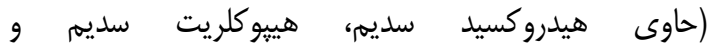

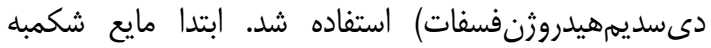

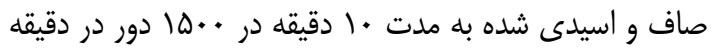

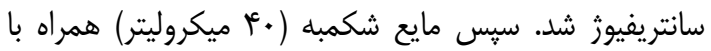

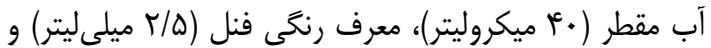

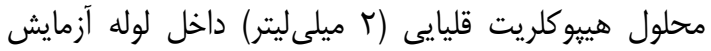

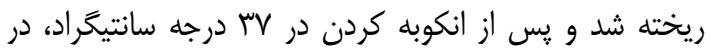

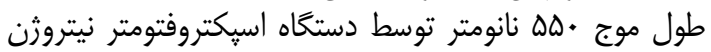

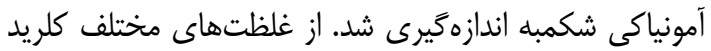

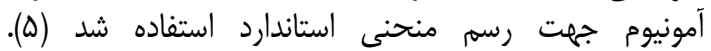

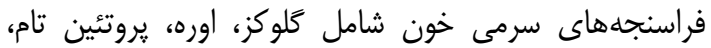

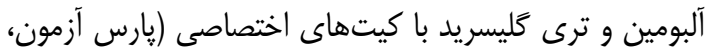

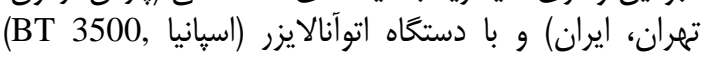

قابليت هضم مواد مغذى مشخص نشده است؛ يُوهشكُران

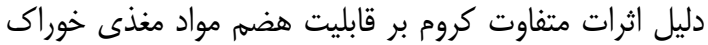

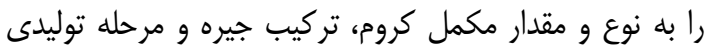

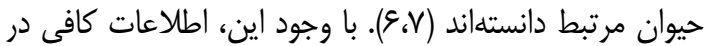

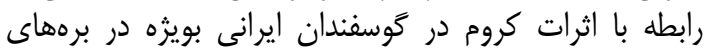

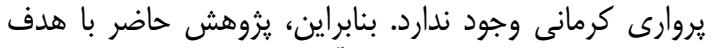

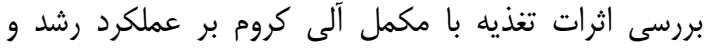

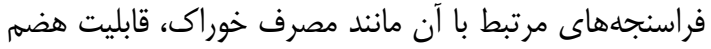

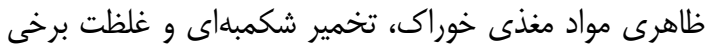
متابوليتهاى خونى در برههاى ثروارى تخدي انجام شد.

\section{مواد و روشها}

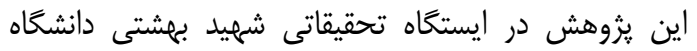

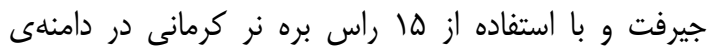

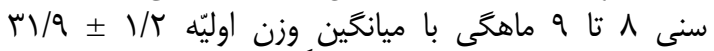

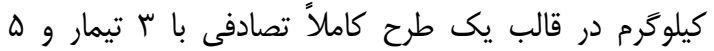

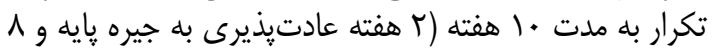

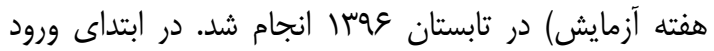

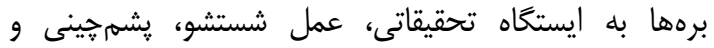

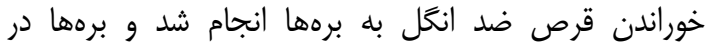

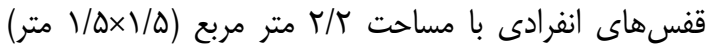

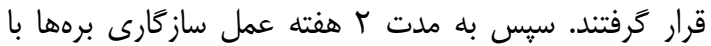

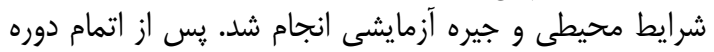

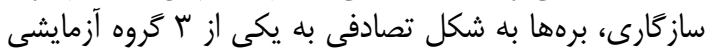

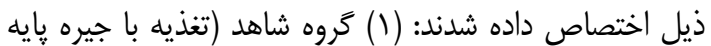

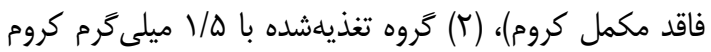

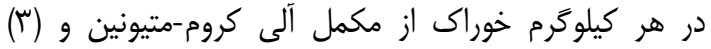

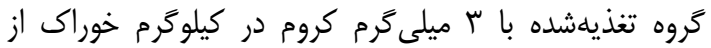

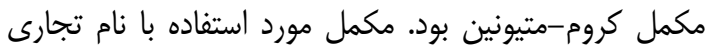

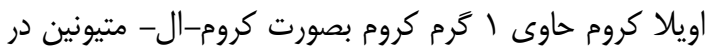

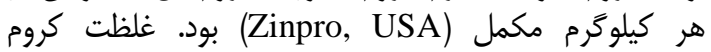

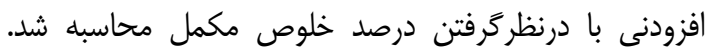

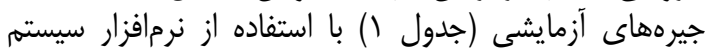

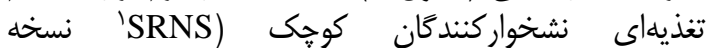

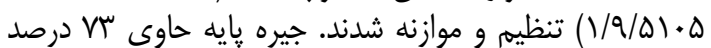

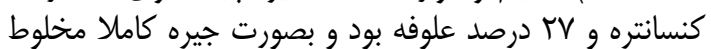

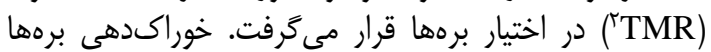

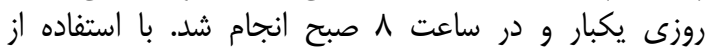

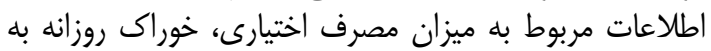

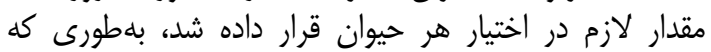

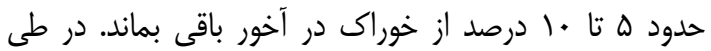

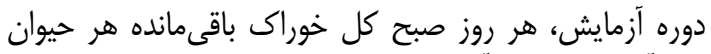

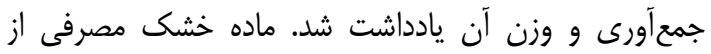
تفريق ماده خشك باقىمانده از ماده خشك آرائه مائه شده برادي

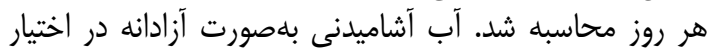

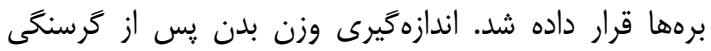

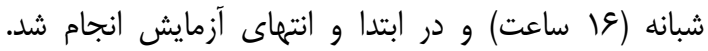
جهت كاهش خطا، وزن كشى در دو دو روز متوالى تكرار آنسار شدان. براى تعيين قابليت هضم ظاهرى مواد مغذى خوراك به به روش 


$$
\text { اندازهّيرى شدند. غلظت كلوبولين از تفريق مقدار آلبومين از بروتئين تام محاسبه شد (ع). }
$$

Table 1. Ingredients and feed composition of basal diet

$$
\text { جدول ا- مواد خوراكى و تركيب مواد مغذى جيره پايه }
$$

\begin{tabular}{|c|c|}
\hline مقدار (كرم در كيلوَرم) مقرم) & ماده خوراكى \\
\hline$r V \cdot$ & يونجه \\
\hline$\Delta \Delta$. & جو \\
\hline 90 & كنجاله سويا \\
\hline$\Delta$. & سبوس كَندم \\
\hline 1. & كربنات كلسيه \\
\hline$\Delta$ & نمكى \\
\hline 1. & مكمل مواد معدنى -ويتامينى' \\
\hline 1. & بيكربنات سديم \\
\hline مقدار (كرم در كيلوكرم) & مواد مغذى جيره \\
\hline$r / \Upsilon \Phi$ & انرزى قابل سوخت و ساز (محاكالرى در كيلوكَرم)' \\
\hline 10 & يروتئين خام \\
\hline $1 \omega / r$ & تربى خام \\
\hline TVQ & الياف نامحلول در شوينده خنثى \\
\hline 179 & الياف نامحلول در شوينده اسيدى \\
\hline qro/s & 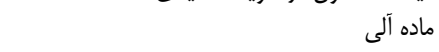 \\
\hline$V \in / F$ & 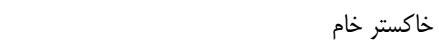 \\
\hline$\Lambda / T^{c}$ & كلسيم' \\
\hline$\Delta / r$ & فسفرץ \\
\hline.$/ 9$ & كروم (ميلى گَرم در كيلوَّرم) \\
\hline
\end{tabular}

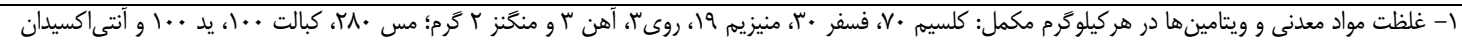

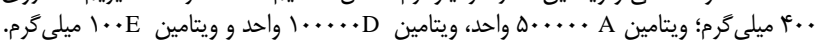
ץ - انرزى قابل سوخت و ساز (مكاكالرى در كيلوكرم جيره) و غلظت عناصر كلسيه و فسفر توسط نرمافزار جيرهنويسى نشخوار كنندكان كوخى (SRNS) محاسبهشده است.

\section{نتايج و بحث مصرف خور اك و عملكرد رشد}

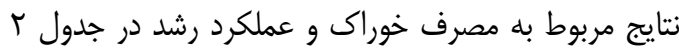

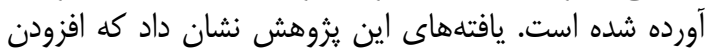

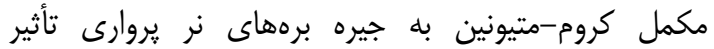

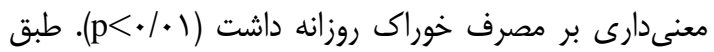

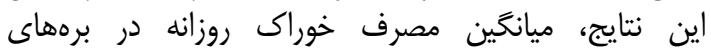

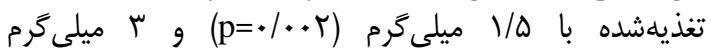

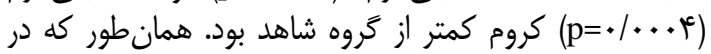

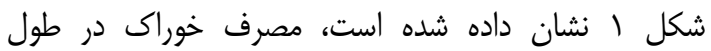

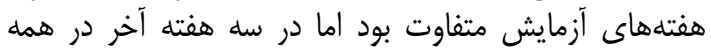

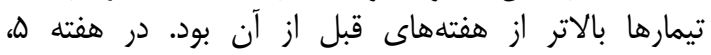

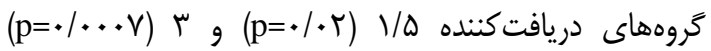

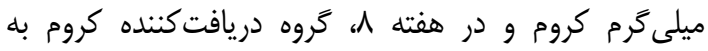

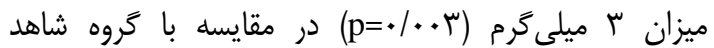

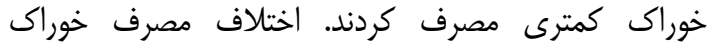

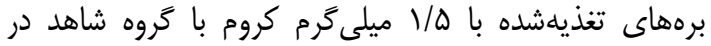

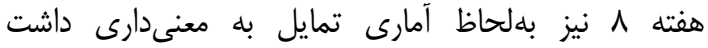
(p=•/هF)

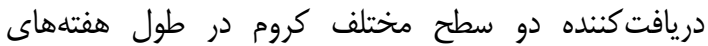
آزمايش تفاوتى وجود نداشت.

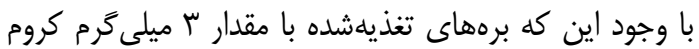

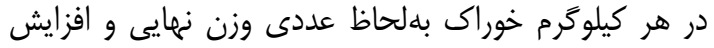

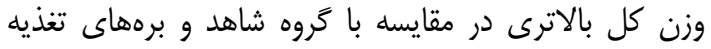

شاخص دمايى-رطوبتى (THI) با استفاده از دادههاى بيشينه و كمينه دما و رطوبت و مطابق فرمول ذيل محاسبه

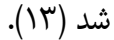

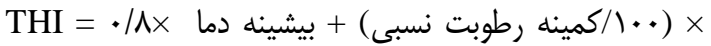
|c/

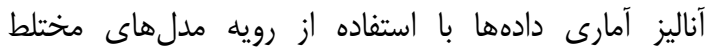

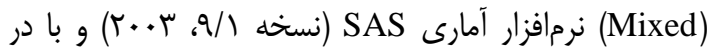

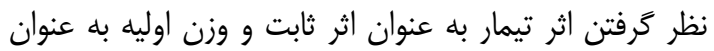

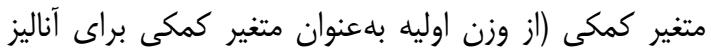

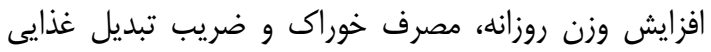

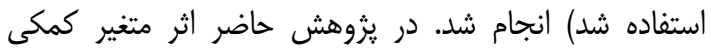

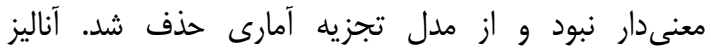

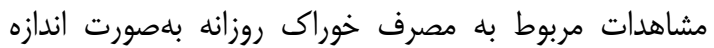

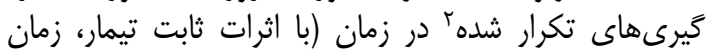

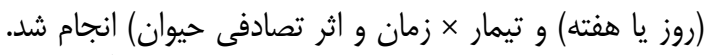

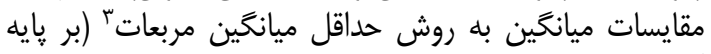

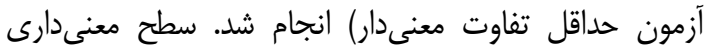

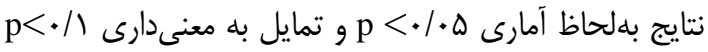

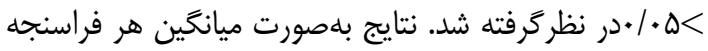

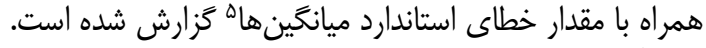
$\mathrm{Y}_{\mathrm{ij}}=+\mathrm{T}_{\mathrm{i}}+\mathrm{e}_{\mathrm{ij}}$ مدل آمارى طرح بايه بهصورت ذيل بودار

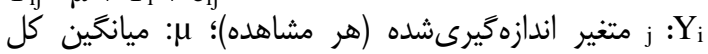
مشاهدات؛ 
مى شود. نتايج اين يزوهش نشان داد كه تغذيه با بَ ميلى كَرم

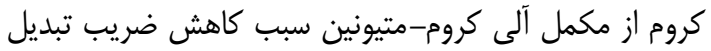

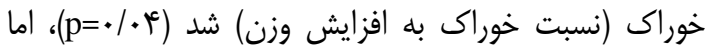

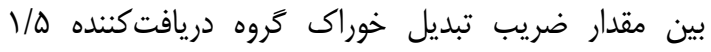

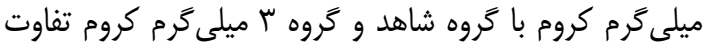

معنى دارى مشاهده نشلد كروم

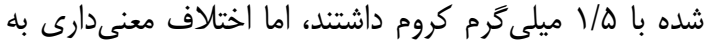

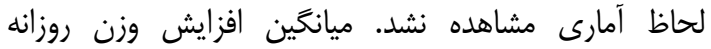

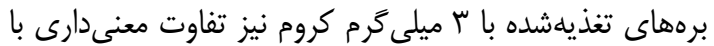

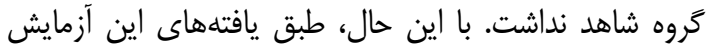

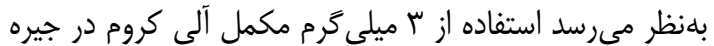

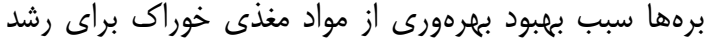

جدول r- تاثير مكمل آلى كروم بر مصرف خوراك و صفات عملكردى برههاى بروارى Table 2. The effect of organic chromium supplement on feed intake and performance of fattening lambs

\begin{tabular}{|c|c|c|c|c|c|}
\hline \multirow{2}{*}{ احتمال معنىدارى } & \multirow{2}{*}{ خطاى استاندارد } & \multicolumn{3}{|c|}{ كروه آزمايشى' } & \multirow{2}{*}{ فراسنجه } \\
\hline & & "َ ميلى گرم كروم & ه/ 1/ ميلى گرم كروم & شاهد & \\
\hline $.1 \ldots 9$ & TI/AFI & $119 \% / \cdot r^{b}$ & $1199 / .{ }^{b}$ & $\mid r \Delta \cdot / / r^{a}$ & مصرف خوراك روزانه (كرم) \\
\hline$\cdot / 9 \cdot r 8$ & $1 / 194$ & rI/ar & rr/qT & $\Gamma r / F \Delta$ & وزن اوليه (كيلوكرم) \\
\hline.$/ 9990$ & 1/Tat & $F T / \mu$. & $\mid 4 / 9$. & FI/KT & وزن نهايى (كيلوگرم) \\
\hline . / rquk & . $/$ QTD & $1 . / \mathrm{WV}$ & N/91 & N/qV & افزايش وزن كل (كيلوگرم) \\
\hline$\cdot / \mu \cdot \cdot 1$ & $q / V T)$ & $19 T / K \Lambda$ & ع & $19 \cdot / 11$ & افزايش وزن روزانه (كرم) \\
\hline$\cdot / \cdot \Delta \cdot \cdot$ &.$/ \mu 1$. & s/r.b & $V / \Delta \cdot a b$ & V/qua & ضريب تبديل خوراى \\
\hline
\end{tabular}

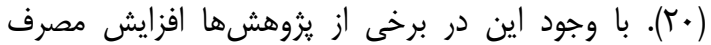

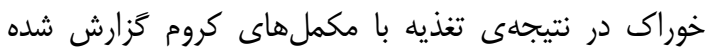

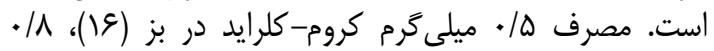

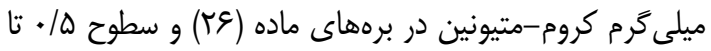

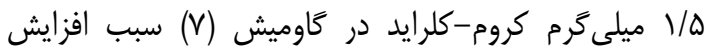

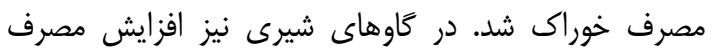

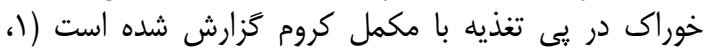

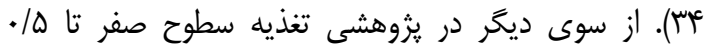

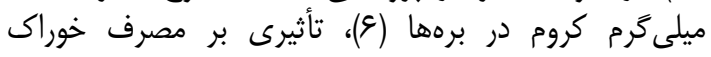
نداشت.
در يثوهش حاضر استفاده از مكمل كروم سبب كاهش

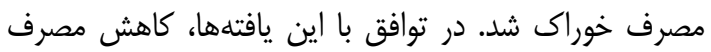

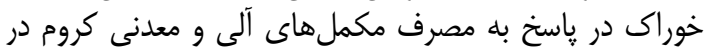

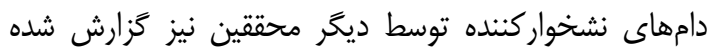

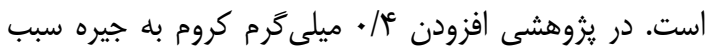

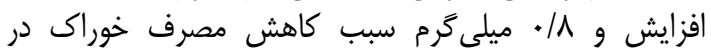

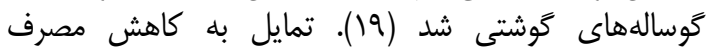

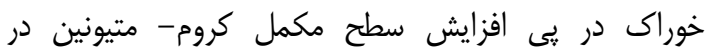

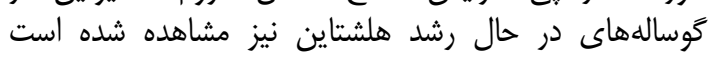

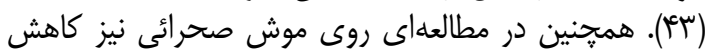

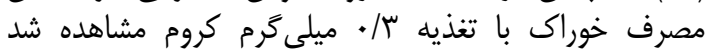

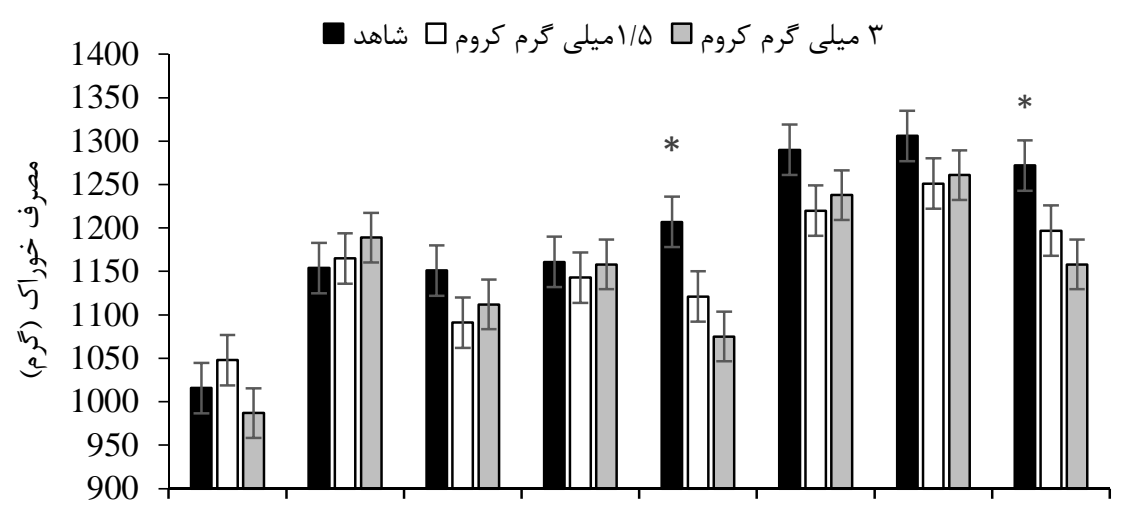

زمان (هفته)

شكل 1- مصرف خوراك هفتكى برههاى تغذيهشده با مكمل آلى كروم

Figure 1. Weekly feed intake of lambs fed with organic chromium supplement

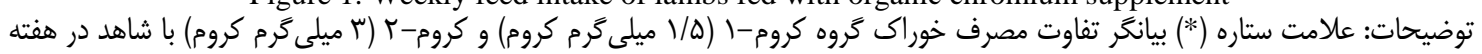

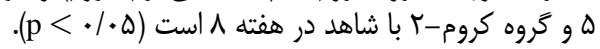


داده است كه شكلهاى مختلف كروم از طريق تفاوت در نرخ

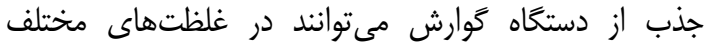

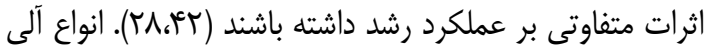

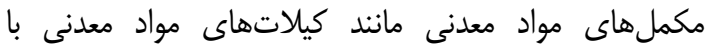

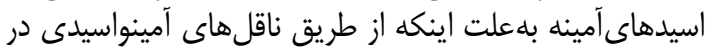

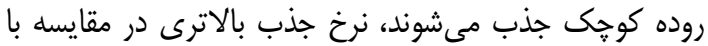

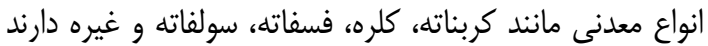

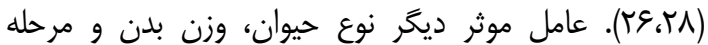

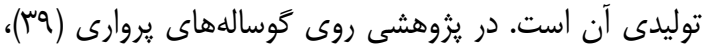

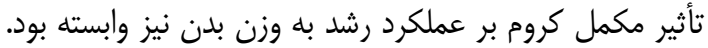

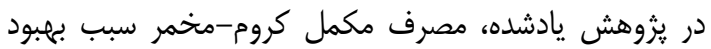

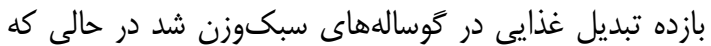

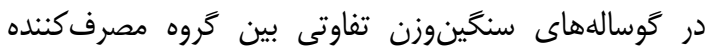

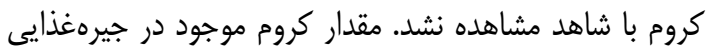

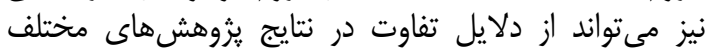

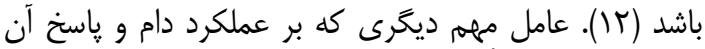

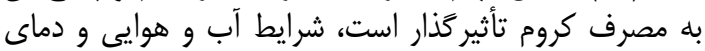

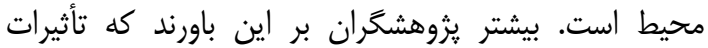

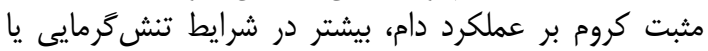

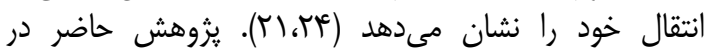

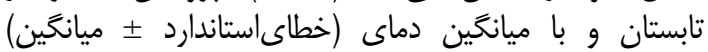
هان

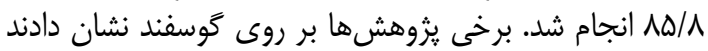

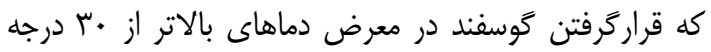

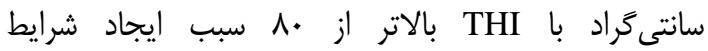

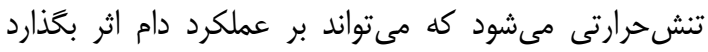

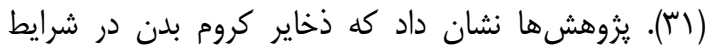

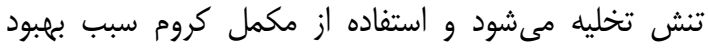

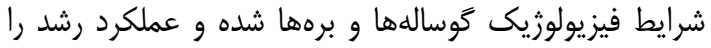

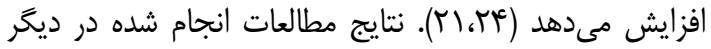

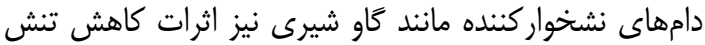

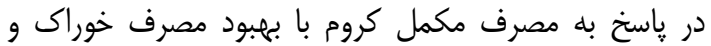

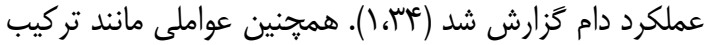

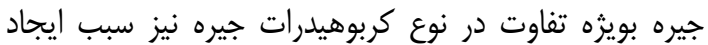

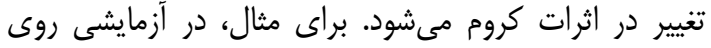

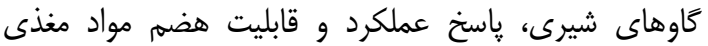

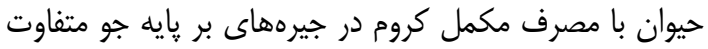

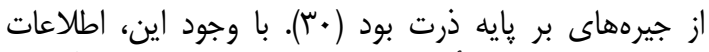

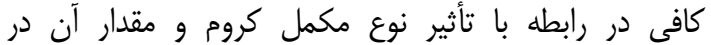

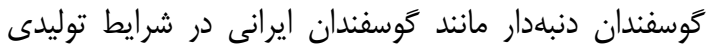

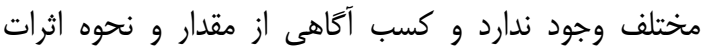
مكمل كروم در كوسفندان بومى نيازمند انجام يزوهش ونهاى

بيشترى است.

قابليت هضم مواد مغذى خور اك

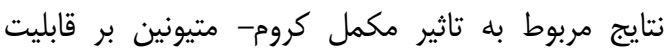

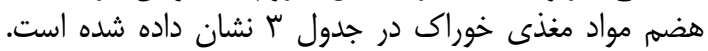

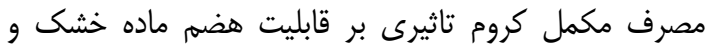
ماده آلى نداشت، با وجود اين، اعداد قاباديليت هضم مادم ماده خشك ماديك

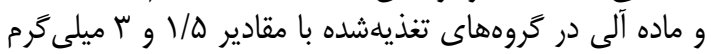

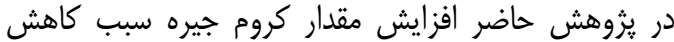

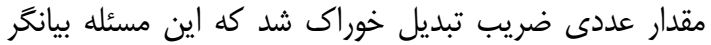

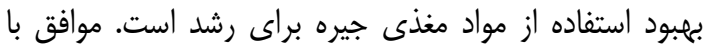

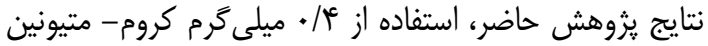

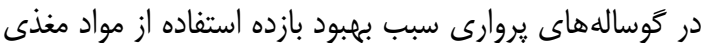

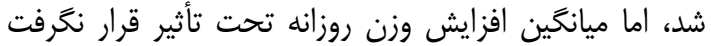

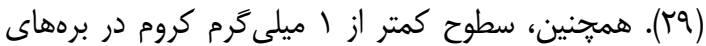

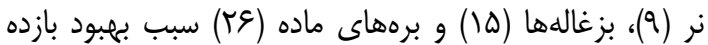

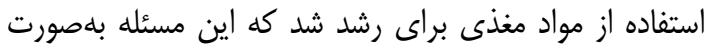

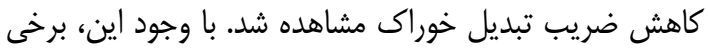

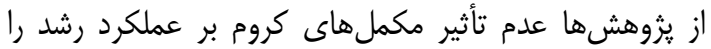

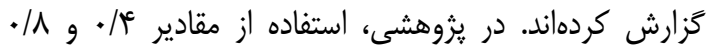

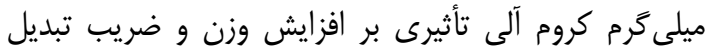

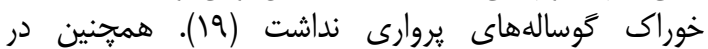

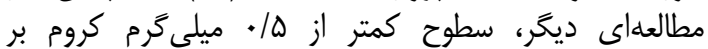

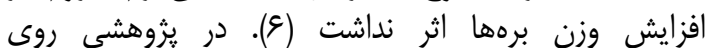

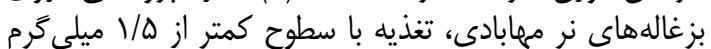

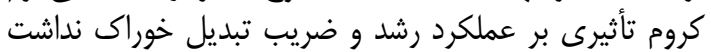

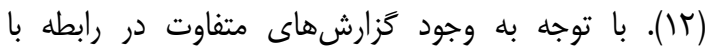

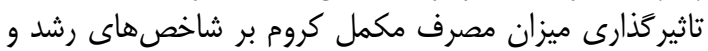

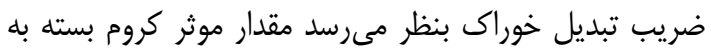

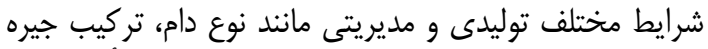

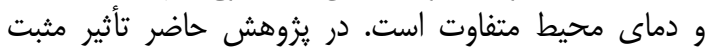

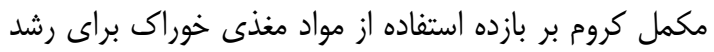

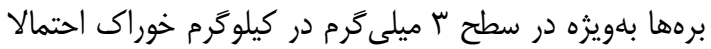

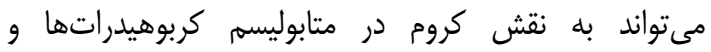

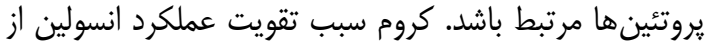

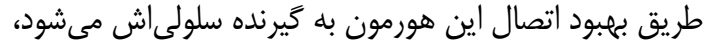

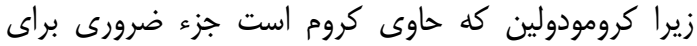

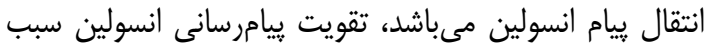

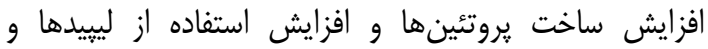

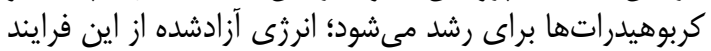

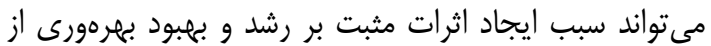

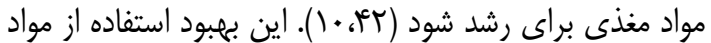

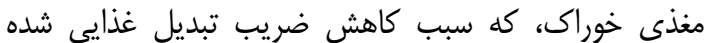

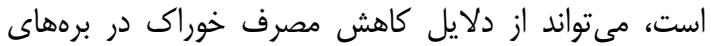

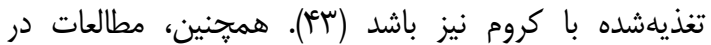

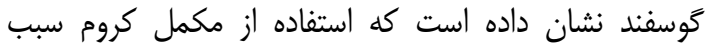

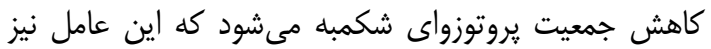

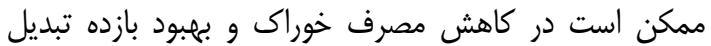

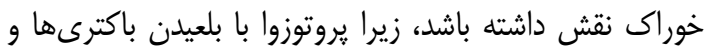

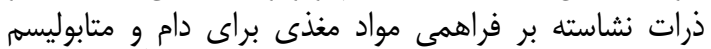

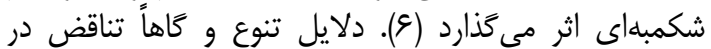

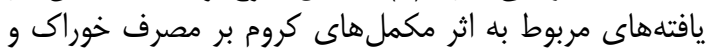

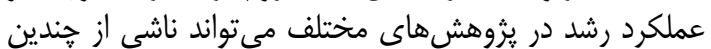

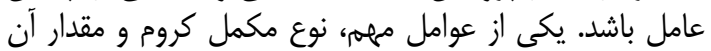

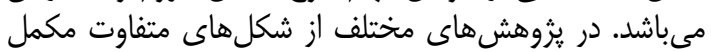

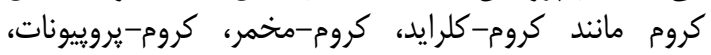
كروم- متيونين و غيره استفاده شده است. يُوهشهران كرومان نشان 


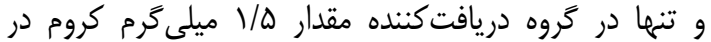

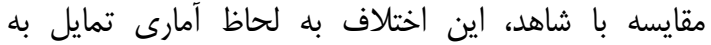

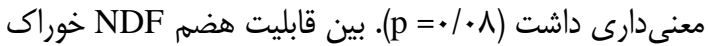

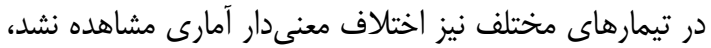

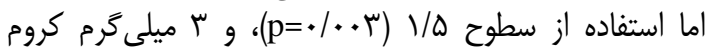

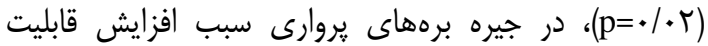
هضم ADF خوراك شد.
كروم در هر كيلوگرم خوراك بالاتر از شاهد بود كه تنها

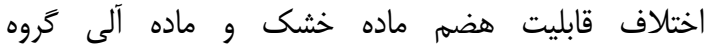

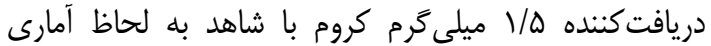

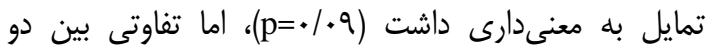

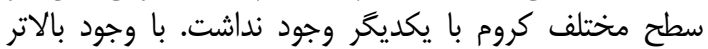

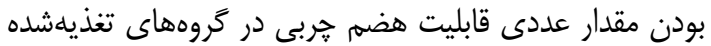

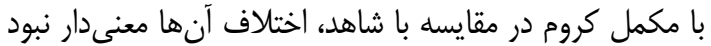

جدول سـ- تاثير مكمل آلى كروم بر قابليت هضم ظاهرى مواد مغذى خوراك برههاى يروارى (درصد) Table 3. The effect of organic chromium supplement on apparent nutrients digestibility of fattening lambs (\%)

\begin{tabular}{|c|c|c|c|c|c|}
\hline \multirow[b]{2}{*}{ احتمال معنىدارى } & \multirow[b]{2}{*}{ خطاى استاندارد ميانكينها } & \multicolumn{3}{|c|}{ كروه آزمايشى' } & \multirow[b]{2}{*}{ ماده مغذى } \\
\hline & & 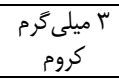 & ه/ ميلى كرم كروم & 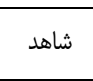 & \\
\hline$\cdot / 4 \cdot 1$. & $1 / 1 \cdot r$ & $V \cdot / g r$ & $V r / r$. & $9 N / 41$ & ماده خشك \\
\hline ./TINA &.$/ 9 T 1$ & $v^{w} / q$. & $V \Delta / . \cdot$ & $V I / . r$ & ماده آلى \\
\hline.$/ 1919$ & $r / v \cdots$ & $\Delta T / V$ & $\Delta \Delta / q 1$ & 4.1 .0 & هربى \\
\hline . /TASQ & r/grt & $F N / F$ & $\Delta 1 / 9$. & $F 1 / 90$ & NDF \\
\hline$\cdot / \cdot \wedge r^{c}$ & $r / 4 / 9$ & $\mu \varphi / / \Lambda^{\mathrm{a}}$ & $\mathcal{F N} / \Delta \mathcal{F}^{\mathrm{a}}$ & $\mu \Psi / V^{b}$ & $\mathrm{ADF}$ \\
\hline
\end{tabular}

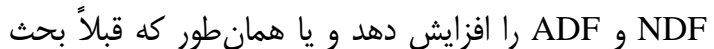

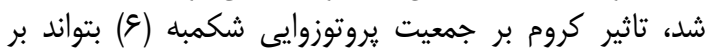

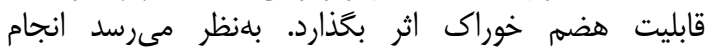

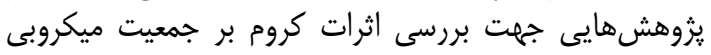

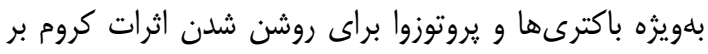

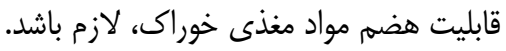

نيتروزن آمونياكى و pH مايع شكمبه

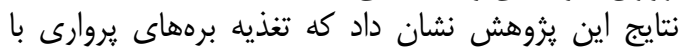

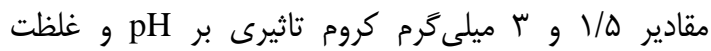

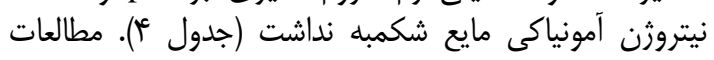

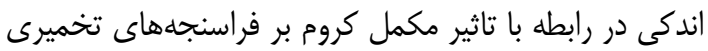

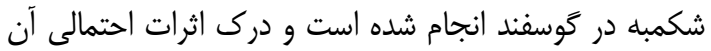

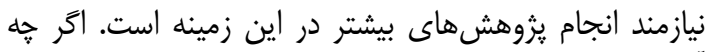

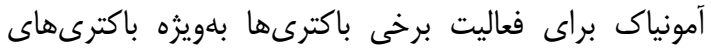

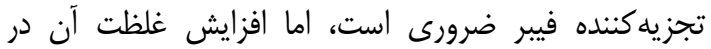

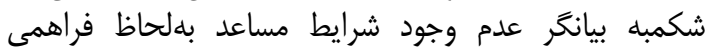

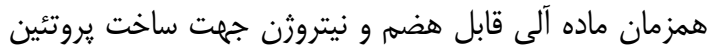

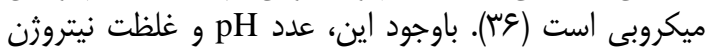

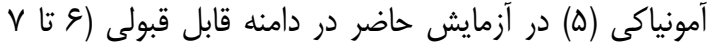

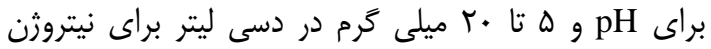

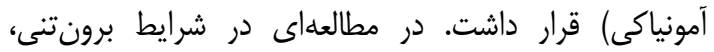

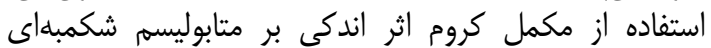

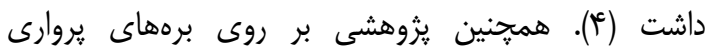

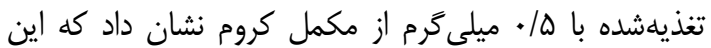

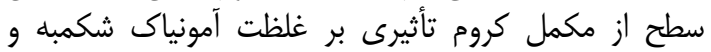

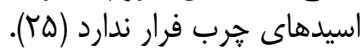

در رابطه با تأثير مكمل كروم بر قابليت هضم مواد

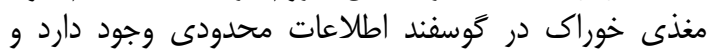

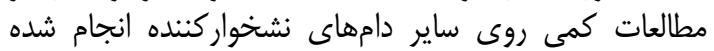

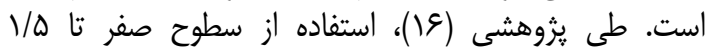

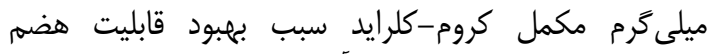

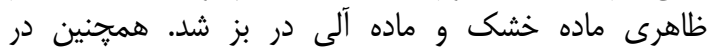

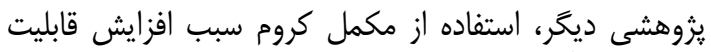

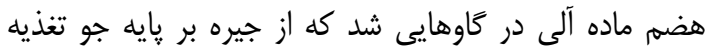

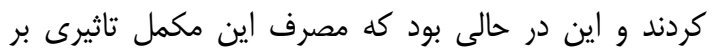

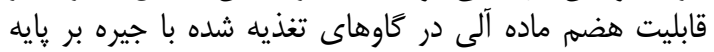

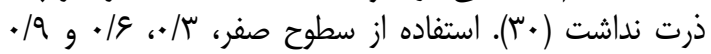

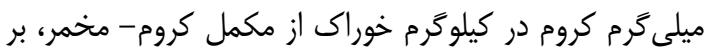

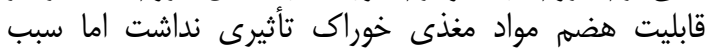

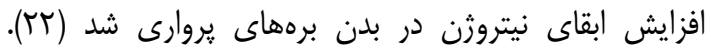

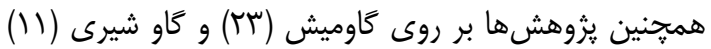

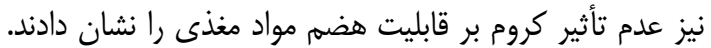

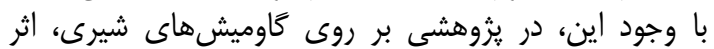

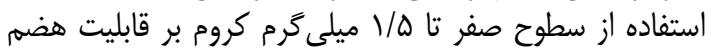

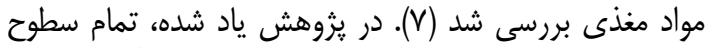

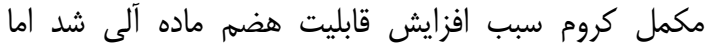

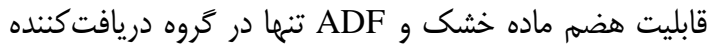

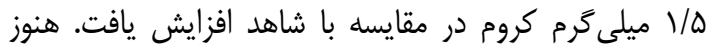

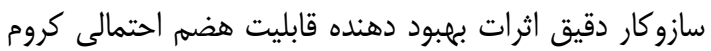

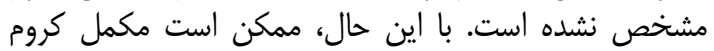

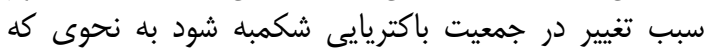

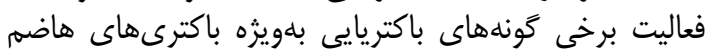


جدول ع- تاثير مكمل آلى كروم بر pH و غلظت نيتروثن آمونياكى مايع شكمبه برههاى يروارى Table 4. The effect of organic chromium supplement on ruminal fluid pH and ammonia nitrogen of fattening lambs

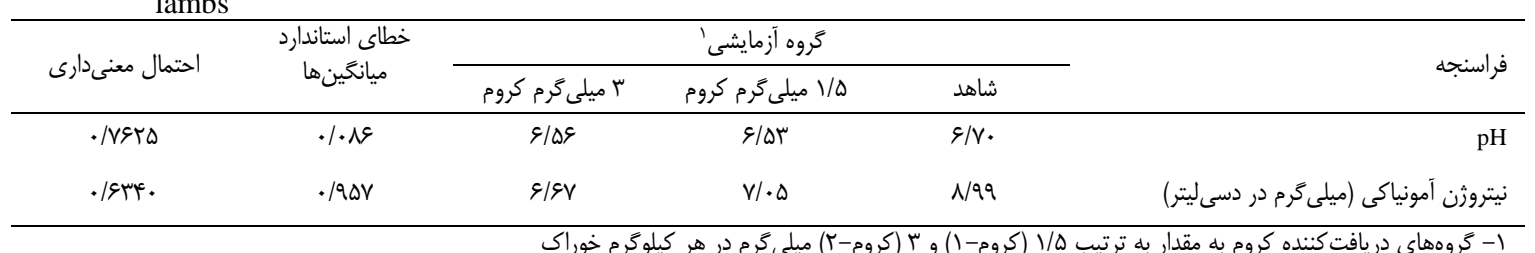

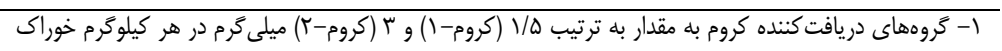

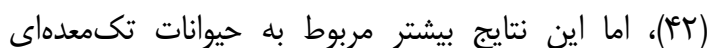

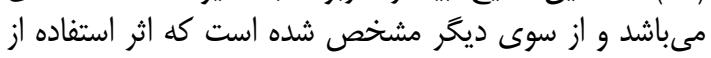

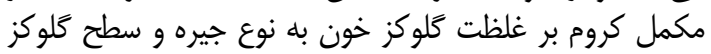

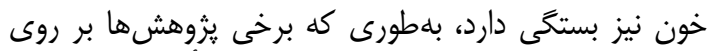

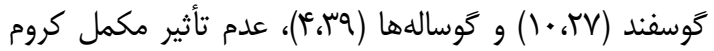

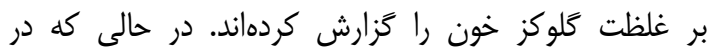

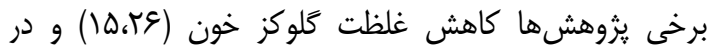

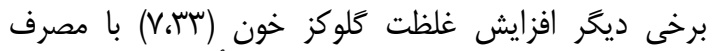

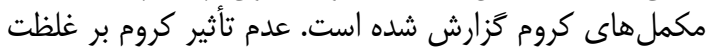

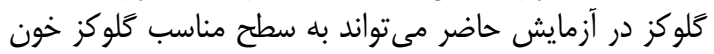

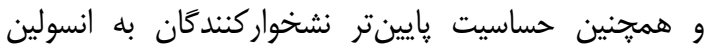
جهت تنظيم قند خون باشد (ه) (1).
متابوليتهاى خون

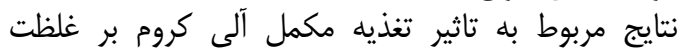

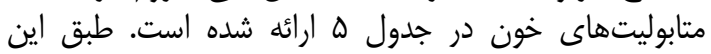

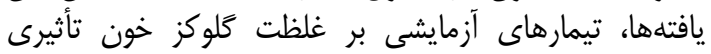

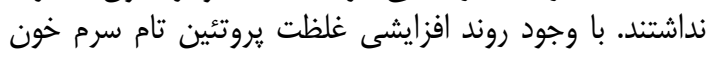

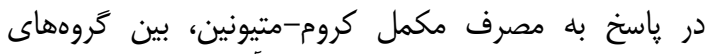

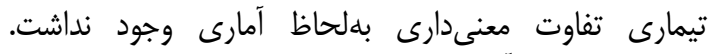

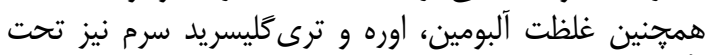

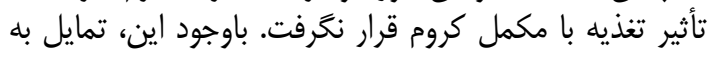

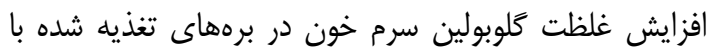

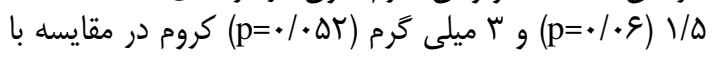

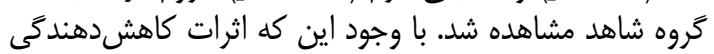
غلظت كلوكز خون توسط مكملهایى كروم اثبات شده است

Table 5. The effect of organic chromium supplement on blood metabolites of fattening lambs

جدول ه- تاثير مكمل آلى كروم بر متابوليتهاى خون برههاى يروارى

\begin{tabular}{|c|c|c|c|c|c|}
\hline \multirow[b]{2}{*}{ احتمال معنى دارى } & \multirow{2}{*}{ خطاى استاندارد } & \multicolumn{3}{|c|}{ 'كروه آزمايشى' } & \multirow[b]{2}{*}{ فراسنجه } \\
\hline & & كريلى كرم & هرو ميلى & 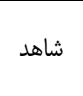 & \\
\hline$\cdot|M|$ & 年 & $\Delta \cdot / \cdot \cdot$ & $\Delta \Gamma / \Lambda$. & $\Delta \Delta / \& 4$ & كلوكز (ميلى گرم در دسىليتر) \\
\hline.$/ F \& \Delta V$ &.$/ 1 r$. & $V / r$. & V/IT & s/Ar & يروتئين تام (كرم در دسىليتر) \\
\hline$\cdot 19 \cdot \cdot 1$ &.$/ .19$ & $r / \uparrow \wedge$ & r/re & $r / T r$ & آلبومين \\
\hline .1 .901 & $\cdot / \cdot v V$ & r/q. & r/N & $r / \Delta r$ & كلوبولين \\
\hline$\cdot|\Gamma \Delta| \cdot$ & $\cdot / M$ & $\mid \mathrm{V} / \cdot \cdot$ & $\mid r / \Lambda$. & $|\omega| \cdot \Delta$ & ترى گليسريد (ميلى گرم در دسىليتر) \\
\hline$\cdot /$ FVaA & $r / \Delta>9$ & $9.1 \cdot r$ & $\Delta \backslash / \Lambda$. & $\Delta S / T$. & اوره (ميلى گُرم در دسى ليتر) \\
\hline
\end{tabular}

برههاى دريافت كننده كروم شايد ناشى از بهبود وضعيت ايمنى نئى

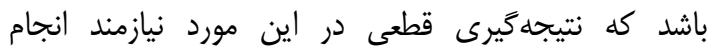

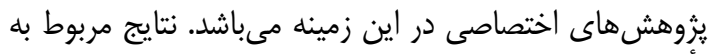

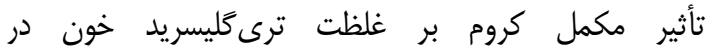

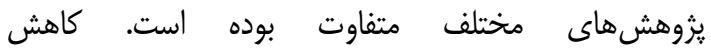

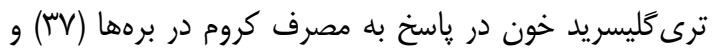

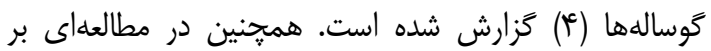

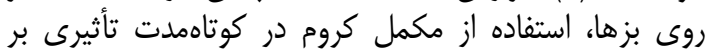

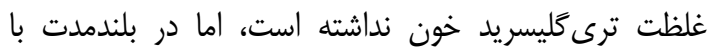

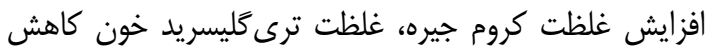

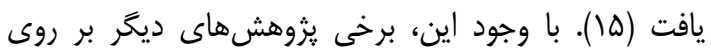

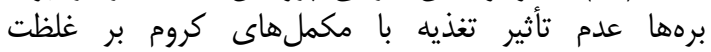

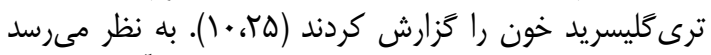

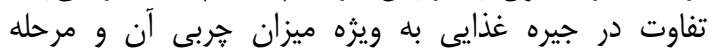

استفاده از مكمل كروم سبب افزايش غلظت يروتئين تام در

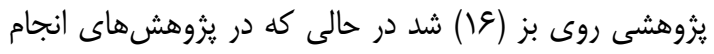

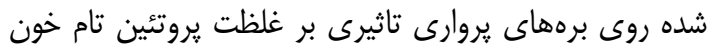

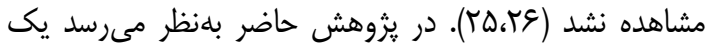

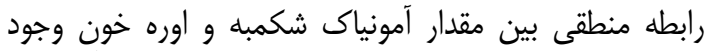

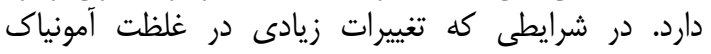

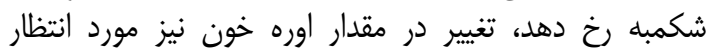

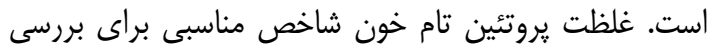

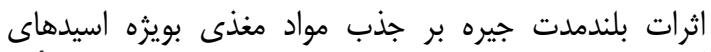

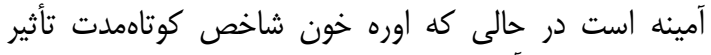

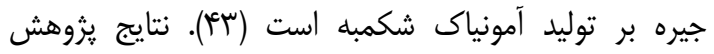

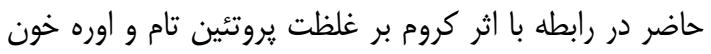

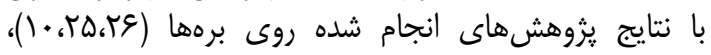

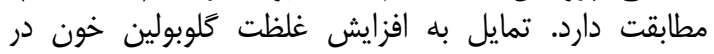




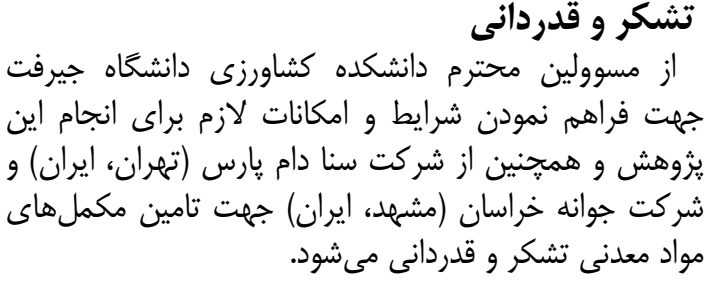

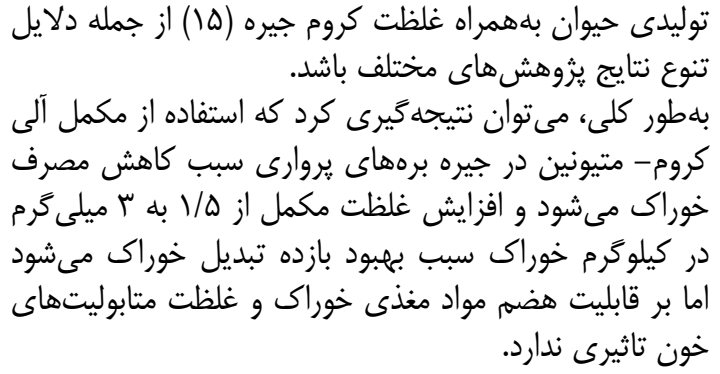

منابع

1. Al-saiady, M.Y., M.A. Al-shaikh, S.I. Al-mufarrej, T.A. Al-showeimi, H.H. Mogawer and A. Dirrar. 2004. Effect of chelated chromium supplementation on lactation performance and blood parameters of Holstein cows under heat stress. Journal of Animal Feed Science and Technology, 117: 223-233.

2. AOAC. 2002. Official methods of analysis. $16^{\text {th }}$ ed. Arlington, USA. $212 \mathrm{pp}$.

3. Arvizu, R.R., I.A. Domínguez, M.S. Rubio, J.L. Bórquez, J.M. Pinos-Rodríguez, M. González and G. Jaramillo. 2011. Effects of genotype, level of supplementation, and organic chromium on growth performance, carcass and meat traits grazing lambs. Journal of Meat Science, 88: 404-408.

4. Besong, S., J.A. Jackson, D.S. Trammell and V. Akay. 2001. Influence of supplemental chromium on concentrations of liver triglyceride, blood metabolites and rumen VFA profile in steers fed a moderately high fat diet. Journal of Dairy Science, 84: 1679-1685.

5. Broderick, G.A. and J.H. Kang 1980. Automated simultaneous determination of ammonia and total amino acids in ruminal fluid and in vitro media. Journal of Dairy Science, 54: 1176-1183.

6. Dallago, B.S.L., C.M. Mcmanus, D.F. Caldeira, A.C. Lopes, T.P. Paim, E. Franco, B.O. Borges, P.H. F. Teles, P.S. Correa and H. Louvandini. 2011. Performance and ruminal protozoa in lambs with chromium supplementation. Research of Veterinary Science, 90: 253-256.

7. Deka, R.S., V. Mani, M. Kumar. Z.S. Shiwajirao and H. Kaur. 2015. Chromium supplements in the feed for lactating Murrah buffaloes (Bubalus bubalis): influence on nutrient utilization, lactation performance and metabolic responses. Journal of Biological Trace Element Research, 168: 362-371.

8. Dikeman, M.E. 2007. Effects of metabolic modifiers on carcass traits and meat quality. Meat Science, 77: 121-135.

9. Ding, J., Z.M. Zhou, L.P. Ren and Q.X. Meng. 2008. Effect of monensin and live yeast supplementation on growth performance, nutrient digestibility, carcass characteristics and ruminal fermentation parameters in lambs fed steam-flaked corn-based diets. Asian-Australasian Journal of Animal Science, 21: 547-554.

10. Domínguez-Vara, I.A., S.S. González-Muñoz, J.M. Pinos-Rodríguez, J.L. Bórquez-Gastelum, R. Bárcena-Gama, G. Mendoza-Martínez, L.E. Zapata and L.L. Landois-Palencia. 2009. Effect of feeding selenium-yeast and chromium-yeast to finishing lambs on growth, carcass characteristics, and blood hormones and metabolites. Journal of Animal Feed Science and Technology, 152: 42 - 49.

11. Eftekhari, M., A. Zali, M. Dehghan Banadaki and M. Ganjkhanlou. 2014. Effect of chromium methionine and energy source on production and nutrient digestibility of Holstein cows in prepartum and postpartum. Iranian Journal of Animal Science, 45: 107-115 (In Persian).

12. Emami, A., M. Ganj khanlou, A. Zali, A. Akbari Afjani and A. Hozhbari. 2015. Effect of chromium supplementation on performance and on carcass characteristics of Mahabadi goat kids. Iranian Journal of Animal Science, 44: 97-104 (In Persian).

13. Garcia-Ispierto, I., F. Lopes-Gatius, P. Santolaria, J.L. Yaniz, C. Nogareda, M. Lopez-Bejar and F. De Renesis. 2006. Relationship between heat stress during the peri-implantation period and early fetal loss in dairy cattle. Theriogenology, 65: 799-807.

14. Ghorbani, A., H. Sadri, A.R. Alizadeh and R.M. Bruckmaier. 2012. Performance and metabolic responses of Holstein calves to supplemental chromium in colostrum and milk. Journal of Dairy Science, 95: 57605769.

15. Haldar, S., S. Mondal, S. Samanta and T.K. Ghosh. 2009a. Effects of dietary chromium supplementation on glucose tolerance and primary antibody response against des petits ruminants in dwarf Bengal goats (Capra hircus). Animal, 3: 209-217.

16. Haldar, S., S. Mondal, S. Samanta and T.K. Ghosh. 2009b. Performance traits and metabolic responses in goats (Capra hircus) supplemented with inorganic trivalent chromium. Journal of Biological Trace Element Research, 131: 110-123.

17. Hayati, S., R. Valizadeh, A. Naserian, A.M. Tahmasebi and A. Mousaie. 2017. The effect of dietary barley grain substitution with hydroponic barley grass on milk yield and some blood metabolites of Saanen lactating goats. Research on Animal Production. 9: 32-38 (In Persian).

18. Kargar, N., M. Moradi Shahre Babak, H. Moravej and M. Rokoie. 2007. The estimation of genetic parameters for growth and wool traits in Kermani sheep. Animal Science journal (Pajouhesh and Sazandegi), 73: 88-95 (In Persian).

19. Kegley, E.B., D.L. Galloway and T.M. Fakler. 2000. Effect of dietary chromium-L-methionine on glucose metabolism of beef steers. Journal of Animal Science, 78: 3177-3183. 
20. Kim, H.S., S.Y. Lee, C.H. Kim, S.J. Ohh, J.S. Shin and K.I. Sung. 2003b. Effects of chromium methionine supplementation on obesity index and serum lipids in rats. Journal of the Korean Society of Food Science and Nutrition, 32: 706-709.

21. Kitchalong, L., J.M. Fernandez, L.D. Bunting, L.L. Southern and T.D. Bidner. 1995. Influence of chromium tripicolinate on glucose metabolism and nutrient partitioning in growing lambs. Journal of Animal Science, 73: 2694-2705.

22. Kraidees, M.S., I.A. Al-Haidary, S.I. Mufarrej, M.Y. Al-Saiady, H.M. Metwally and M.F. Hussein. 2009. Effect of supplemental chromium levels on performance, digestibility and carcass characteristics of transport-stressed lambs. Asian-Australasian Journal of Animal Science, 22: 1124-1132.

23. Kumar, M., H. Kaur, A. Tyagi, V. Mani, R.S. Deka, G. Chandra and V.K. Sharma. 2013. Assessment of chromium content of feedstuffs, their estimated requirement, and effects of dietary chromium supplementation on nutrient utilization, growth performance, and mineral balance in summer-exposed buffalo calves (Bubalus bubalis). Journal of Biological Trace Element Research, 155: 29-37.

24. Moonsie-Shageer, S. and D.N. Mowat. 1993. Effect of level of supplemental chromium on performance, serum constituents, and immune status of stressed feeder calves. Journal of Animal Science, 71: 232-238

25. Mosayebi, M., H. Aliarabi and A. Farahavar. 2017. Effect of adding organic chromium and L-carnitine to feedlot lamb's diet on performance, glucose metabolism and some blood parameters. Journal of Ruminant Research, 5: 81-110 (In Persian).

26. Mousaie, A., R. Valizadeh, A.A. Naserian, M. Heidarpour and H. Kazemi Mehrjerdi. 2014. Impacts of feeding selenium-methionine and chromium-methionine on performance, serum components, antioxidant status and physiological responses to transportation stress of Baluchi ewe lambs. Journal of Biological Trace Element Research, 162: 113-123.

27. Mousaie, A., R. Valizadeh and M. Chamsaz. 2017. Selenium-methionine and chromium-methionine supplementation of sheep around parturition: impacts on dam and offspring performance. Journal of Archives of Animal Nutrition, 71: 134-149.

28. NRC. 2005. Mineral Tolerance of Animals. National Academies Press, Washington, DC. USA. 183 pp.

29. Ohh, S.J. and J.Y. Lee. 2005. Dietary chromium-methionine chelate supplementation and animal performance. Asian-Australasian Journal of Animal Science, 18: 898-907.

30. Sadri, H., G.R. Ghorbani, H.R. Rahmani, A.H. Samie, M. Khorvash and R.M. Bruckmaier. 2009. Chromium supplementation and substitution of barley grain with corn: Effects on performance and lactation in periparturient dairy cows. Journal of Dairy Science, 92: 5411-5418.

31. Sevi, A., G. Annicchiarico, M. Albenzio, L. Taibi, A. Muscio and S. Dell Aquila. 2001. Effects of solar radiation and feeding time on behavior, immune response and production of lactating ewes under high ambient temperature. Journal of Dairy Science, 84: 629-640.

32. Shrivas, K. and N.K. Jaiswal. 2013. Dispersive liquid-liquid microextraction for the determination of copper in cereals and vegetable food samples using flame atomic absorption spectrometry. Food Chemistry, 141: 2263-2268.

33. Smith, K.L., M.R. Waldron, L.C. Ruzzi, J.K. Drackley, M.T. Socha and T.R. Overton. 2008. Metabolism of dairy cows as affected by pre-partum dietary carbohydrate source and supplementation with chromium throughout the pre-parturient period. Journal of Dairy Science, 91: 2011-2020.

34. Soltan, M.A. 2010. Effect of dietary chromium supplementation on productive and reproductive performance of early lactating dairy cows under heat stress. Journal of Animal Physiology and Animal Nutrition, 94: 264-272.

35. Suttle, N.F. 2010. Mineral nutrition of livestock. $4^{\text {th }}$ ed. CABI, Wallingford, Oxford shire, UK. 579 pp.

36. Taheri, H.R. and M. Tavakoli Alamuti.2011. Animal nutrition science. $1^{\text {th }}$ ed. Aeeizh publication, Tehran, Iran, 432 pp (In Persian).

37. Uyanik, F. 2001. The effects of dietary chromium supplementation on some blood parameters in sheep. Journal of Biological Trace Element Research, 84: 93-101.

38. Valizadeh, R. 2014. Sheep and goat production. $3^{\text {th }}$ ed., Ferdowsi University of Mashhad publication, Mashhad, Iran, 376 pp (In Persian).

39. Van Bibber-Krueger, C.L., J.E. Axman, J.M. Ganzalez, C.I. Vahl and J.S. Drouillard. 2016. Effects of yeast combined with chromium propionate on growth performance and carcass quality of finishing steers. Journal of Animal Science, 94: 3003-3011.

40. Van Soest, P.J., J.B. Robertson and B.A. Lewis. 1991. Methods for dietary fiber, neutral detergent fiber, and non-starch polysaccharides in relation to animal nutrition. Journal of Dairy Science, 74: 3583-3597.

41. Vincent, J.B. 2000. The biochemistry of chromium. Journal of Nutrition, 130: 715-718.

42. Vincent, J.B. 2007. The nutritional biochemistry of chromium (iii). Elsevier, Amesterdam, 293 pp.

43. Yari, M., A. Nikkhah, M. Alikhani, M. Khorvash, H. Rahmani and G.R. Ghorbani. 2010. Physiological calf responses to increased chromium supply in summer. Journal of Dairy Science, 93: 4111-4120. 


\title{
The Effect of Organic Chromium Supplement on Growth Performance, Nutrients Digestibility and Some Ruminal Fermentation parameters and Blood Metabolites in Fattening Lambs
}

\section{Asma Seifalinasab $^{1}$, Amir Mousaie ${ }^{2}$, Morteza Sattaei Mokhtari ${ }^{3}$ and Hossein Doumari ${ }^{3}$}

1 and 3- M.Sc. Student and Assistant professor, Department of Animal Sciences, Faculty of Agriculture, University of Jiroft

2- Assistant professor, Department of Animal Sciences, Faculty of Agriculture, University of Jiroft, (Corresponding author: moosaee.amir@gmail.com) Received: Jun 26, $2018 \quad$ Accepted: November 28, 2018

\begin{abstract}
In the present study, fifteen Kermani male lambs with average body weight of $31.9 \pm 1.2 \mathrm{~kg}$ were used in a completely randomized design with 3 treatments and 5 replicates each, for 10 weeks including 2 weeks of adaptation to basal diet and 8 weeks of data collection. The experimental groups were (1) control group (without chromium-methionine (Cr-Met) supplementation), (2) lambs fed with $1.5 \mathrm{mg} \mathrm{Cr} / \mathrm{kg}$ diet of Cr-Met, and (3) lambs received $3 \mathrm{mg}$ $\mathrm{Cr} / \mathrm{kg}$ of $\mathrm{Cr}-\mathrm{Met}$ supplement. The results showed that average daily feed intake of lambs received $1.5(\mathrm{p}=0.002)$ and $3(\mathrm{p}=0.0004) \mathrm{mg} / \mathrm{kg}$ of $\mathrm{Cr}$ supplement was higher than that of the control animals. Chromium supplement had no influence on final body weight and average daily gain, however, feed conversion ratio decreased in lambs fed with $3 \mathrm{mg} / \mathrm{kg}$ diet of $\mathrm{Cr}$ supplement $(\mathrm{p}=0.04)$. The digestibility coefficients of dry matter, organic matter, fat and neutral detergent fibre (NDF) were not affected by the experimental treatments; however, acid detergent fibre (ADF) digestibility was higher in lambs fed with $1.5(\mathrm{p}=0.003)$ and $3(\mathrm{p}=0.02)$ $\mathrm{mg} \mathrm{Cr} / \mathrm{kg}$ of diet than those fed the control diet. Chromium supplement had no significant effects on $\mathrm{pH}$ and ammonia nitrogen $\left(\mathrm{NH}_{3}-\mathrm{N}\right)$ concentration of ruminal fluid. Similarly, serum glucose, total protein, albumin, globulin, triglyceride and urea concentrations were not different among experimental groups. It can be concluded that feeding $3 \mathrm{mg} / \mathrm{kg}$ diet of $\mathrm{Cr}-\mathrm{Met}$ supplement improves feed conversion efficiency of fattening lambs. Moreover, both Cr-Met levels decrease feed intake and increase ADF digestibility.
\end{abstract}

Keywords: Ammonia nitrogen, Chromium-methionine, Digestibility, Fattening lamb, Weight gain 